\title{
A CASE OF WEGENER'S GRANULOMATOSIS
}

\author{
BY \\ A. M. THOMAS \\ From the Area Laboratory, Musgrove Park Hospital, Taunton
}

(RECEIVED FOR PUBLICATION MARCH 28, 1957)

In 1931 Klinger described a case of polyarteritis nodosa with an unusual localization of the lesions in the nasal septum, lungs, spleen, and kidneys. Wegener $(1937,1939)$ reported three more similar cases as a new disease, stressing its granulomatous aspect. Since that time, examples of this condition have appeared in the literature under a confusing variety of different names, but recent authors have preferred the term "Wegener's granulomatosis," and the present state of our knowledge of this subject is summarized by Fahey, Leonard, Churg, and Godman (1954) and by Godman and Churg (1954). In two excellent papers they review the literature, describe seven new cases and clarify the diagnostic criteria of this disease. The present paper describes another case of Wegener's granulomatosis and discusses its relationship with some cases of Ceelen's haemosiderosis. The story of the case and its investigations will be more readily understood if it is appreciated that it presented as an intractable anaemia and was investigated and treated as such. Indeed, apart from haemoptysis, thought to originate from an ulcer of the nasal septum, symptoms referable to the respiratory system were extremely slight.

\section{Case History}

D. F. M., a butcher aged 40 , first went to see his doctor in January, 1949, on account of "rheumatism." He had no fever but complained of painful, swollen joints which improved in a few days.

On February 28 he was sent to a chest clinic with a note from the doctor specifying cough, haemoptysis, and night sweats.

The clinic notes stated that cough had been present for several weeks, sputum, 1-2 oz., blood-stained for several days, pain in the left chest on and off. The appetite, bowels, kidneys, and bladder were normal. The fingers were not clubbed. The patient did not suffer from lassitude or loss of weight, but was in poor general condition. A few moist sounds were heard at the apex of the left lung, and a chest radiograph suggested right basal bronchiectasis.

A review of the radiograph showed a thickened right interlobular pleura and generally increased bronchovascular shadows with possibly diffuse fine? fibrosis.

On March 23 the patient was sent to the chest clinic complaining of haemoptysis every morning? after "a cold" at Christmas, 1948, and also of $\vec{\sigma}$ multiple septic skin lesions. On examination, ulcers? on the nasal septum and right inferior turbinate and a punched ulcer on the palate immediately above the $\vec{r}$ uvula were seen. The Wassermann reaction was negative. He was given potassium iodide, and on March 30 he had an "iodine" rash and herpes? labialis. The Wassermann reaction was still nega- $\overrightarrow{0}$ tive. By April 13 the palate ulcer had healed, but septal bleeding continued. On May 17 a biopsy of the septal ulcer showed chronic inflammatory, non-O specific granulation tissue, with no evidence of tuberculosis or malignancy.

On June 5 urticaria was noted. Haemoglobin was $56 \%$.

On June 13 he was sent to E.N.T. Department with letter: "A large slough separated from his righto nostril to-day. During last fortnight he has had $a_{\supset}^{3}$ septic throat. Recurrent herpes, angioneurotic oedema of face and urticaria. His general condition:has not been too good and he has been in bed for종 some of the time."

An E.N.T. note on June 15 read: "His trouble is due to some obscure general condition. There is no enlargement of his liver or spleen." During hiso stay in hospital (three weeks) he ran a temperature of 99.4 $4^{\circ}$ F. on three evenings, otherwise he was praco? tically apyrexial.

On October 6 his doctor wrote to the hospital :을 “M. had severe herpes around mouth and eyes. He came home from hospital about six weeks ago somewhat better, but has recently developed a septiq toe-? ingrowing toe nail. About ten days ago कo diffuse purpuric rash appeared, which is still presentw He has had no pyrexia, but complains of rheumatie pains and general weakness."

On October 7 he attended hospital as an out patient complaining of nasal catarrh and haemoptysis? which has been very slight since his operation. Hej did not feel well and had noticed herpes of the righ 5 eye, pains in both shoulders, slight cough, rash orip the arms and legs, chiefly, for one month.

On examination, the right eye was seen to be in尺 jected. Purpura was everywhere, also septic spots? Nothing abnormal noted in heart, chest, and abdomen 
He was admitted to hospital on November 4. Hoarseness was getting worse.

On examination, he was rather pale, both eyes were infected, and he was very hoarse. He had a large ulcer on the left side of the palate, also septic spots and a purpuric eruption on the arms and legs. Blood pressure was $150 / 90 \mathrm{~mm}$. Hg. Otherwise nothing abnormal was detected.

On November 7 R.B.C.s were 3.7 million and $\mathrm{Hb}$ $44 \%$, and on November 9 two pints of blood (packed cells) were given.

By January 13, 1950, the ulcer on the palate was much larger, and also there was a sore on the scrotum.

On January 18 two pints of blood (packed cells) were given.

On January 20 he had an ulcer at base of the right index finger on the back of the hand. Two pints of blood were given on February 12.

The patient's condition declined steadily during the last month, and at the end, when he was unable to swallow on account of the extensive ulceration of the throat, his deterioration was rapid. He collapsed and was in coma for two days before he died on February 15, after being ill for 14 months. There was nothing in the clinical picture to suggest massive infarction of the lungs.

Radiographs taken on February 28 and November 7,1949 , showed a progressive condition (Figs. 1 and 2). In the first there is throughout both lungs a general increase in bronchovascular markings with patchy congestion, particularly marked at the right

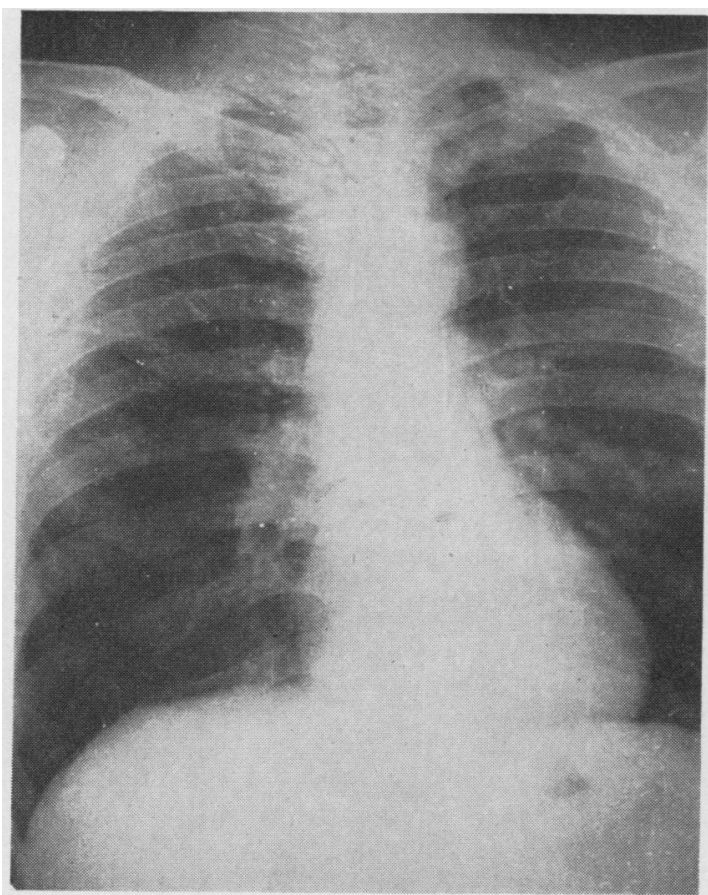

Fig. 1.-First radiograph of the chest on February 28, 1949. base and in the cardiophrenic angle. In the second film the condition is the same, but the general markings are finer and there are less mottled congestive areas. In a later film taken on January 10, 1950, there was a general fine striated appearance of both lungs, giving a ground-glass effect and suggesting a general fine fibrosis of both lungs.

\section{Pathological Examinations}

Haematology.-Between June, 1949, and February, 1950, 13 erythrocyte counts and haemoglobin estimations were performed. The counts varied between 2.9 and 4.2 million per c.mm. and the haemoglobin levels between 44 and $88 \%$ (Haldane), averaging approximately 50 to $60 \%$ with occasional rises after transfusion. The colour index was usually about 0.7 to 0.8 but rose to 1.0 a month before death. During the above period, 11 leucocyte counts were performed and the numbers ranged from 5,000 to 11,000 per c.mm. Polymorphs varied between 87 and $57 \%$; eosinophils were noted on five occasions and varied between 1 and $2 \%$. Three sternal marrow examinations were performed and the first two showed micronormoblastic erythropoiesis which was less severe in the third sample. All three tests showed hyperplastic marrow such as one finds with a secondary anaemia.

Reticulocytes.-5.0, 1.5, and $1.0 \%$ on December 14 and December 29, 1949, and January 10, 1950, respectively.

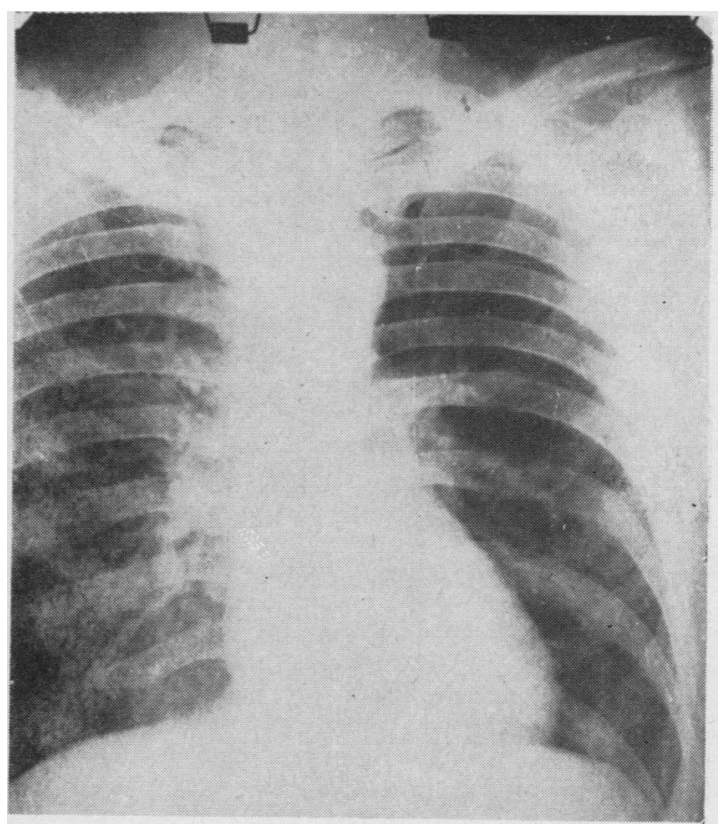

FIG. 2.-Second radiograph of the chest on November 7, 1949. 
Platelets. $-510,000,500,000$, and 480,000 per c.mm. on October 7 and November 7, 1949. and January 10, 1950. respectively.

Bleeding Time.-This was 3 minutes 15 seconds on July 15, 1949 (normal, 2 to 4 minutes).

Coagulation Time (Dale and Laidlaw).-This was 3 minutes on July 15.1949 (normal, $1 \frac{1}{2}$ to 2 minutes).

The erythrocyte sedimentation rate (Westergren) was $68 \mathrm{~mm}$. in one hour on July 26, 1949.

Erythrocyte Fragility.-Haemolysis began at $0.48^{\circ}$ ", and was complete at $0.40^{\circ}$, sodium chloride on February 3, 1950.

Serology.-Wassermann and Kahn tests were negative on March 23, March 30, and November 11. 1949.

Biochemistry. - A van den Bergh test was negative on January 17, 1950. The following results were obtained on February 3:

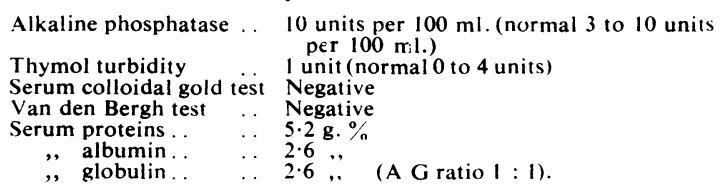

\section{Necropsy}

Necropsy was performed on February 15, 1950, 18 hours after death.

External Examination.-The body is that of a pale, thin man of middle age. There are no purpuric haemorrhages, jaundice, or oedema. The dorsum of the right hand and the scrotum each show an ulcer $4 \mathrm{~cm}$. in diameter. These are deep, penetrating ulcers with irregular, serpiginous edges, but they appear indolent and without surrounding induration. congestion, or inflammation.

Respiratory System.-The lungs present a striking appearance and bulge from the opened thorax. They are solid, voluminous, and fail to collapse when removed from the body. To the touch they are rubbery with firmer, ill-defined, rounded nodules scattered throughout their substance and measuring up to $2 \mathrm{~cm}$. in diameter; they give the tactile impression of being condensations of fibrous tissue within a general diffuse pulmonary fibrosis. The lungs themselves are of a mottled red colour, varying from rust to dark blood red in places. There are occasional pale areas, notably at the right apex, but these are very scanty. The cut surface shows many haemorrhages and haematomata of varying ages, the older in some instances appearing to coincide with firm nodules. There is no evidence of pulmonary neoplasm or inflammation. Pleural adhesions and effusions are abscnt. The hilar lymph nodes are enlarged up to $2 \mathrm{~cm}$. in diameter. but are quite soft. The trachea and bronchi contain blood-sta'ned, frothy fluid. The palate is extensively ulcerated and covered with foul. necrotic debris.
Excretory System. - The kidneys are very pale and show moderately good demarcation of the cortex and medulla. They are of normal size and their capsules strip easily.

Cardiovascular System.-The heart is of normal size and without endocarditis or right ventricular hypertrophy.

The organs of the alimentary. reticulo-endothelial, and central nervous systems appear normal apart from extreme pallor.

\section{Histology}

Lungs.-The lungs show virtually no normal parenchyma and the following changes are found in varying proportions:

(1) Diffuse fibrosis with concentration of older collagen into ill-defined nodular areas (Fig. 3).

(2) There are many diffusely scattered small haemorrhages, each consisting of a group of involved alveoli. The haemorrhages appear to be of different ages, many of them recent. Some of the older haemorrhages seem to be related to the fibrous conglomerations.

(3) Heavy infiltration with siderophages, these being $\vec{\bullet}$ frequently concentrated into dense aggregations $\infty$ (Fig. 4). The amount of haemosiderin in these lungs is very large indeed.

(4) The minimal changes visible are collagenous thickening and diminished vascularity of the alveolar walls.

(5) An occasional group of alveoli is seen containing inflammatory exudate.

(6) Changes in the lung blood vessels consist of:

(a) Recent thrombosis of a few medium-sized vessels with patchy perivascular inflammation.

(b) Calcerosiderosis, distortion, and fragmentation of the elastica of many small vessels (Fig. 5).

(c) Acute arteritis of three small vessels with narrowing of the lumen, necrosis and fibrin deposition in the wall, destruction of the elastica, and perivascular leucocytic infiltration (Figs. 6 and 7). There is a zone of recent haemorrhage surrounding these veisels.

(7) The bronchial lymph nodes show numerous siderophages and carbon particles.

(8) The bronchi show thickening of the walls and sometimes notable cuffing with siderophages and in- $\sigma$ flammatory cells including lymphocytes, histiocytes. N and plasma cells. The lumina of the bronchi ma! $\mathrm{N}$ contain blood, desquamated epithelial cells. and a $\omega$ few siderophages.

(9) Destruction of elastic fibres in some alveolarce walls and blood vessels.

Kidneys.-The kidneys show the following changes:

(1) About $20 \%$ of the glomeruli are abnormal, and these appear to be grouped together rather than $\frac{\vec{D}}{\mathbb{D}}$ scattered evenly throughout the renal parenchyma.? The most common lesion is fibrosis of the tufts vary- $\mathbb{D}$ ing from slight collagenous thickening of the capillary membranes to dense scarring of the whole or part of the tuft (Fig. 8). 


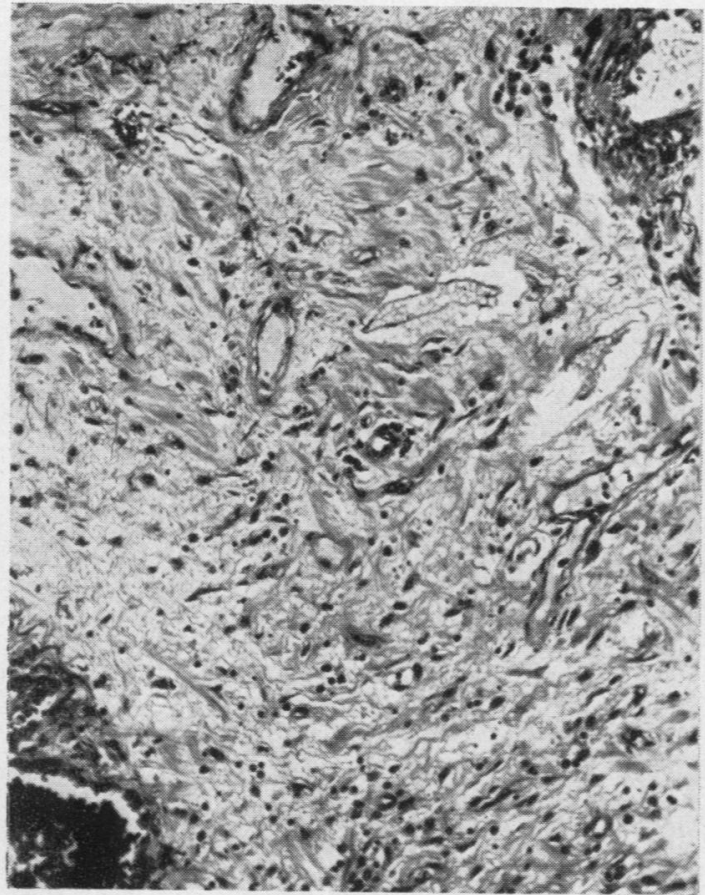

FIG. 3. Section of lung showing diffuse fibrosis. Haematoxylin and eosin, $\times 94$.

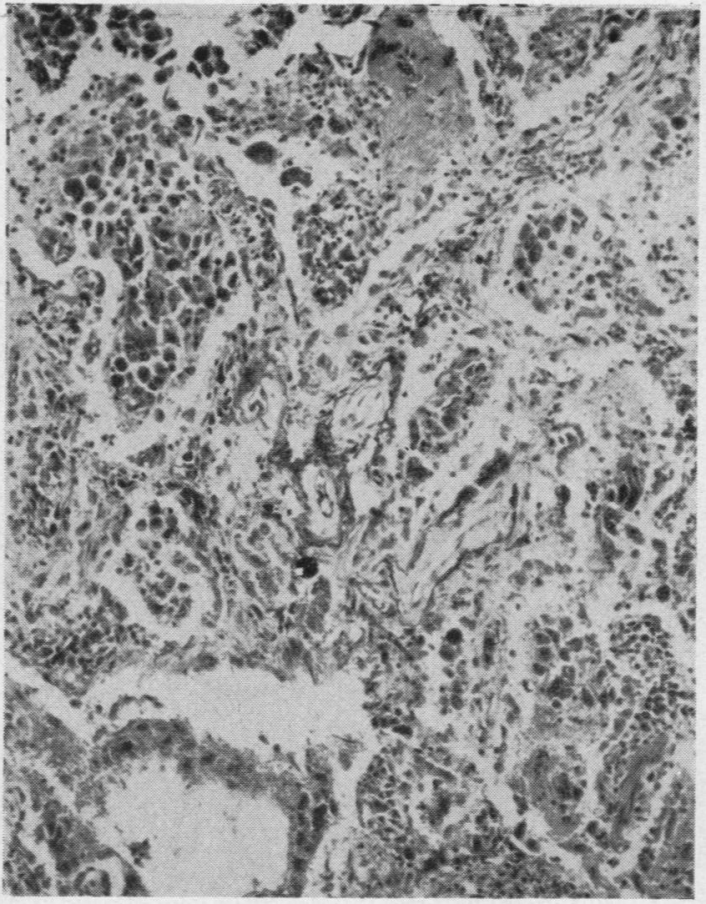

FIG. 4.-Section of lung showing large groups of siderophages. Haematoxylin and eosin, $\times 94$.

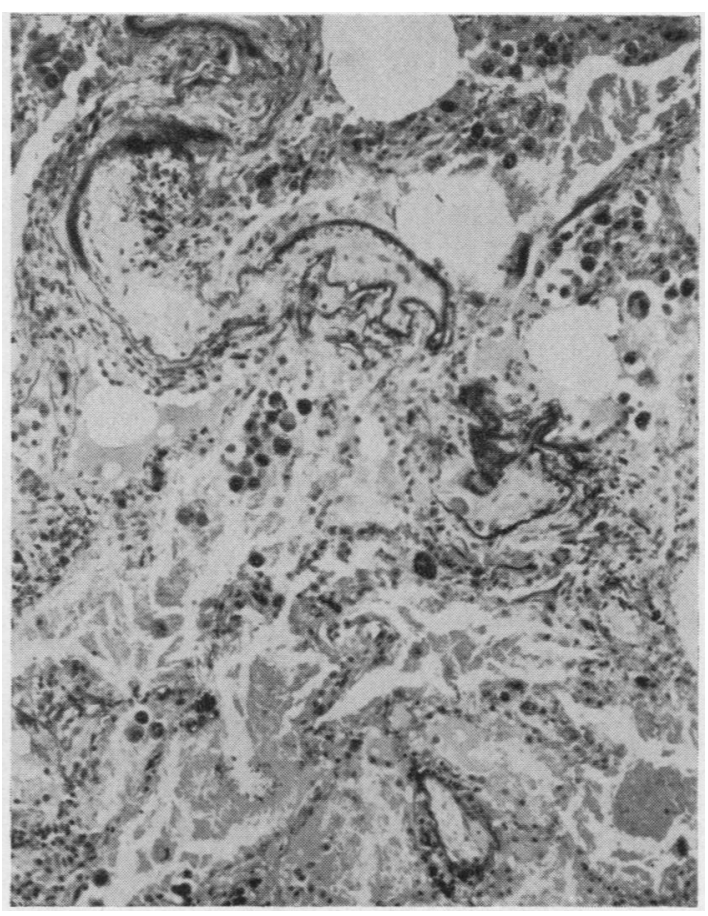

Fig. 5.-Section of lung showing calcero-siderosis of the elastica with distortion and fragmentation. Haematoxylin and eosin, $>94$.

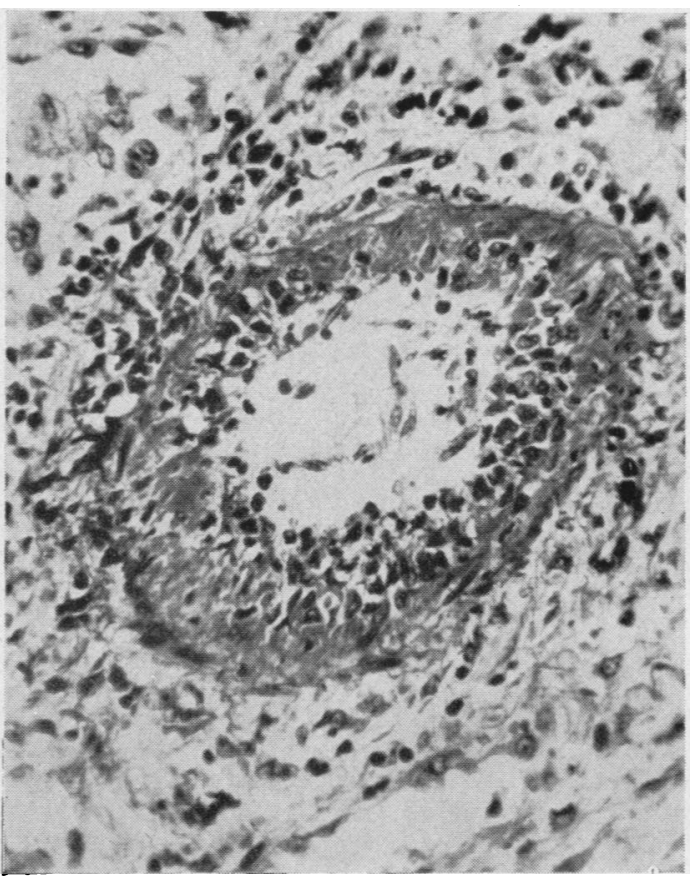

FIG. 6. Section of lung showing necrotizing arteritis with destruction of elastica. Verhoeff's elastin with Masson's blue trichrome, 240. 


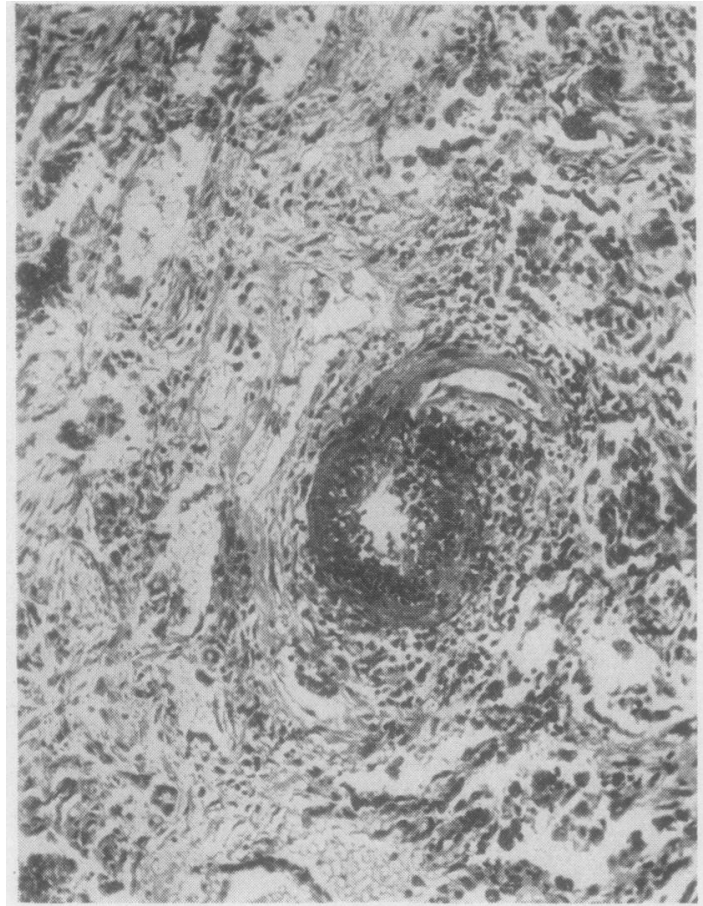

Fio. 7

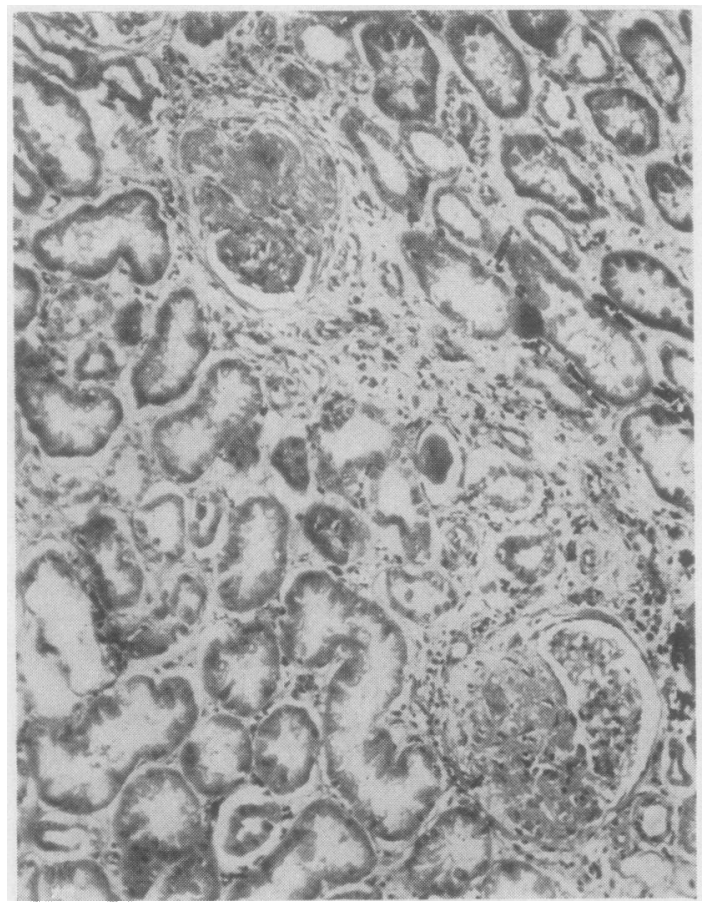

Fio. 8

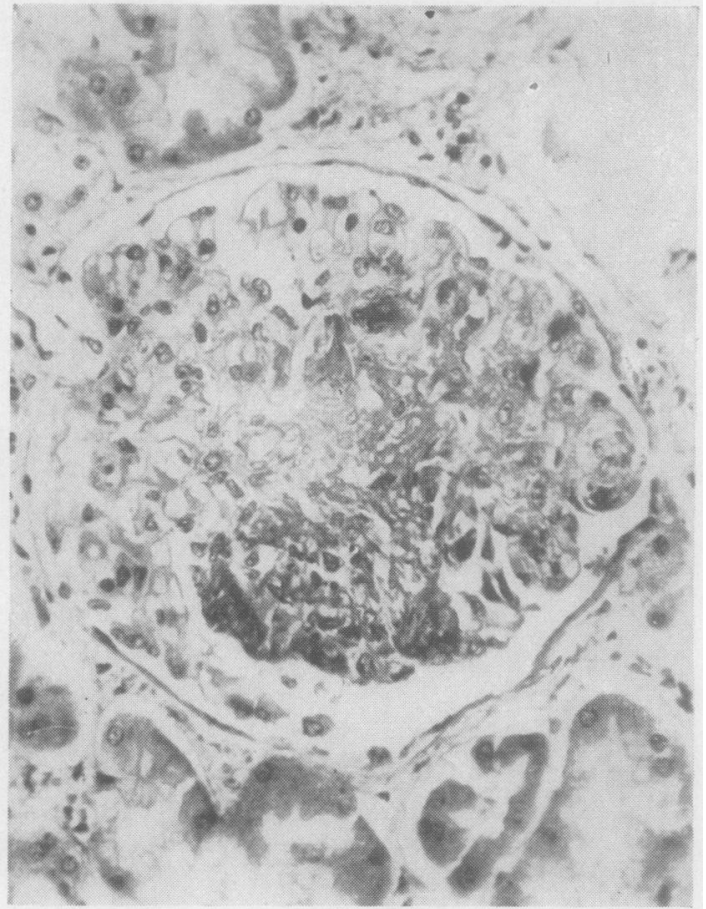

Fio. 9

(2) Some glomeruli show focal necrosis of part of the tuft. This may be associated with adhesive capsulitis (Figs. 9 and 10). Changes in the basement membrane of Bowman's capsule and epithelial proliferation within the capsule with demilune formation occur rarely.

(3) The tubules, especially the descending loops of Henle, show lipochrome aggregations in some epithelial cells. A few tubules contain red blood cells. hyaline and haematoxyphil material. Fatty change and desquamation of epithelial cells are not noted. There is no siderosis of the kidneys.

(4) The renal blood vessels appear normal apart from patchy fibroblastic thickening of the intima.

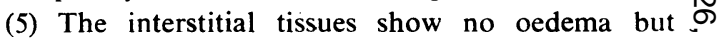
some increase in collagen, particularly in the neigh- $N$ bourhood of diseased glomeruli. A few groups of $\mathcal{N}_{\mathrm{W}}$ inflammatory cells are present.

FIG. 7. - Section of lung showing a second vessel, near to that in Fig. 6 and similarly affected. Verhoeff's elastin with Masson's blue trichrome, $\times 94$.

FIG. 8. Section of kidney showing glomeruli, one with partial and the other almost complete fibrosis. Haematoxylin and eosin. $\frac{Q^{+}}{\Phi}$ 94.

FIG. 9.-Section of kidney showing focal necrotizing glomerulitis. Haematoxylin and eosin, $\times 240$. 


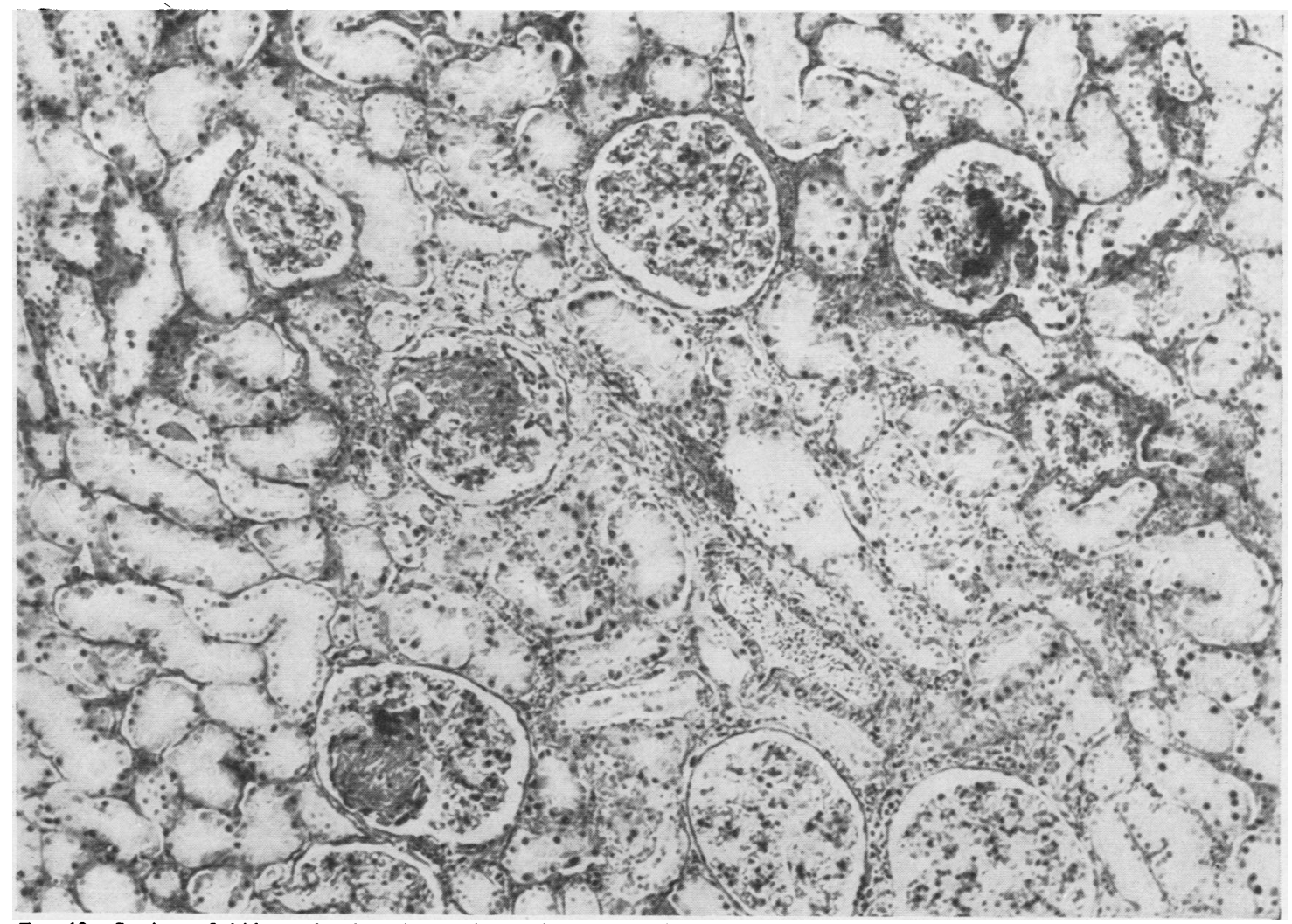

Fig. 10. - Section of kidney showing glomeruli, one (top right) with an acute fibrin deposit; a second (left centre) with fibrotic replacement; and a third (lower left) with a recent fibrin deposit at its centre. Picro-Mallory method, $\times 110$.

Liver.-The liver shows extensive lipochrome infiltration of the parenchyma, particularly in the central cells, less in the portal region and least in the mid-zone. There is no siderosis or fibrosis of the liver, such as occurs in haemochromatosis. A microscopic area of vasculitis is noted.

Ulcers.-These, from the skin and palate, show extensive acute inflammatory changes with variable necrosis. Eosinophils are not numerous. Diphtheroids appear to be the predominant organism in the palatal ulcer. No necrotizing arteritis was noted.

Heart.-The heart shows atheroma and narrowing of the lumen of the interventricular branch of the left coronary artery.

Spleen.-The spleen shows a notable plasmacelled infiltration. The main structure is well preserved and no necrosis or arteritis was seen.

\section{Discussion}

The chief points of interest about this case are, first, its recognition as an example of Wegener's granulomatosis as distinct from polyarteritis nodosa, and secondly its relationship to Ceelen's haemosiderosis and the possibility that the latter may thereby be explained.

Syndrome of Nasal Granuloma, Pulmonary Angiitis, and Focal, Necrotizing Glomerulitis.The coincidence of nasal granuloma and pulmonary arteritis was first reported by Klinger (1931), who described two cases of polyarteritis nodosa with what he called " an unusual localization of the predominant lesions in the spleen and lungs." Actually he was attempting to define a group of cases within the disease polyarteritis, but his group would nowadays be regarded as too illdefined to merit recognition. The real interest in his paper lies in his first case, which began with disease of the maxillary antrum followed by ulceration of the nose and nasal septum; at necropsy the spleen and lungs presented arteritic changes and in the kidneys there was patchy or complete fibrosis or hyalinization of the glomeruli.

Wegener (1937) designated this disease as a " rhinogenic granulomatosis" with special involve- 
ment of the arterial system and of the kidneys. This definition was elaborated by Godman and Churg (1954), who state that Wegener's granulomatosis is always characterized by the three following features: "(1) Necrotizing granulomatous lesions in the upper air passages or in the lower respiratory tract or both; (2) generalized focal necrotizing vasculitis, involving both arteries and veins, almost always in the lungs and more or less widely disseminated in other sites ; (3) glomerulitis characterized by necrosis (and thrombosis) of loops or lobes of the capillary tuft, capsular adhesion and evolution as a glomerular lesion."

The chief difference between the diagnostic criteria of Godman and Churg (1954) and those of Wegener $(1937,1939)$ lies in the localization of the initial granuloma, and recent examples justify the extension of the definition to include all cases starting with a respiratory tract granuloma instead of restricting it to those of nasal origin. This disease, like other types of polyarteritis nodosa, presents so many variable features that only confusion results from regarding any one or two of these features as diagnostic. Wegener's original definition includes all that is constant and can be improved only by expanding the term "rhinogenous" to " respiratory" granulomatosis. Other lesions, which occur frequently but are not diagnostic, include pulmonary, renal, and splenic granulomatosis, which may or may not be associated with necrotizing arteritis. Fever, joint pains, and cutaneous lesions are often found, and the clinical picture is usually governed by the site of the initial granuloma. Leucocytosis, elevation of the erythrocyte sedimentation rate, and anaemia are the principal haematological findings. Widely differing degrees of severity may be encountered and most recorded examples are far more acute and severe than the present case. Its chronicity no doubt accounts for many of its unusual features including the lack of visceral granulomata, pyrexia, and leucocytosis and for the presence of a low-grade, intractable anaemia and the intense pulmonary haemosiderosis.

The main object in defining Wegener's granulomatosis is to differentiate a particular variety of polyarteritis nodosa distinguished by the presence of an initial respiratory tract granuloma, the involvement of only small vessels (veins as well as arteries), and the granulomatous evolution of the disease. The present case satisfies all these criteria, although the preponderance of haemosiderotic changes in the lungs and the cutaneous position of the secondary granulomata are atypical features. The type of vascular lesion in the viscera, including the lungs, and the characteristic focal lesions in the glomeruli, clearly resemble $\overrightarrow{\vec{\rho}}$ drug-induced vascular disease and the other hyper- $\overline{0}$ ergic affections of the blood vessels ("hyper- $\frac{\bar{O}}{0}$ sensitivity angiitis" of Zeek, Smith, and Weeter $\overline{\bar{c}}$. (1948), "hyperergic fibrinous vasculosis" of $\stackrel{\square}{\varrho}$ Lendrum (1956) ) far more than classical polyarteritis nodosa. So close is the similarity that it ${ }^{\infty}$ seems reasonable to regard the upper respiratory $\vec{O}$ tract granuloma as the source of an allergen to $\overrightarrow{\vec{\omega}}$ which all the other manifestations can be attri- $\stackrel{\sim}{\sim}$ buted.

A tentative diagnosis of Wegener's granulomatosis may often be made on the clinical history $\vec{i}$ of nasal or paranasal ulceration followed by signs $\overrightarrow{-}$ and symptoms of polyarteritis nodosa, but in the $\vec{\sigma}$ end the proof is histological, depending on the $\frac{\text { ? }}{2}$ demonstration of pulmonary, renal, and possibly visceral vasculitis. It must be realized that these 3 lesions are essentially focal and may be very scanty. This is probably responsible for much of $\stackrel{\Im}{\supset}$ the confusion in the literature concerning cases $\vec{\theta}$ such as that of Alexander (1954) where an arter- $\infty$ itic lesion in the viscera can only be presumed from the gross description.

In the past some writers have adopted a quite different pathological pattern to characterize these cases, and, coupled with the use of over $a \stackrel{\unrhd}{\unrhd}$ dozen different titles, this has led to indescribable $\overrightarrow{\vec{A}}$ chaos in the literature. The two terms causing $\frac{0}{3}$ most confusion have been " giant-cell granuloma " and "malignant granuloma" of the nose. The former was used by Howells and Friedmann (1950) and by Seidelin and Willcox (1954) too describe undoubted cases of Wegener's granulo- $\frac{-}{3}$ matosis. The epithet "giant-cell" is particularly. undesirable, because the presence or absence ofo these cells in the lesions has little diagnostic value. Their presence may represent a reactive idio-은 syncrasy of the patient, similar to the capricious 7 eosinophilia of some cases of polyarteritis nodosa rather than a diagnostic characteristic of then disease. The journals of otology and laryngology contain a number of these cases under a variety of titles, the commonest of which are "malignant $\omega$ granuloma" (Woods, 1921) and "lethal granu웅 loma" (Stewart, 1933). Their relationship too Wegener's granulomatosis must remain obscure because the early workers were so preoccupied? with the unfruitful study of the initial respiratory tract granuloma that no search appears to have been made for visceral arteritic lesions, even in those cases subject to necropsy. Some cases of lethal granuloma, such as that of Alexandep (1954), may well be examples of Wegener's granu 
lomatosis; others almost certainly are not, and these include the case of McBride (1897) and the first two cases presented by Williams (1949), who made an extensive but unsuccessful search for visceral arteritic lesions. Moreover, Stratton, Price, and Skelton (1953) failed to find vasculitis in necropsy material from four cases of malignant granuloma, and Woodburn and Harris (1951) found evidence of polyarteritis nodosa in only one of six cases of lethal ulceration of the nose and face.

The number of cases collected from the literature by Fahey et al. (1954) and Godman and Churg (1954) is 22, to which they add a further seven of their own. Details of 11 more examples of Wegener's granulomatosis, together with the present case, are given in Table $I$, and this now brings the total up to 41 . In addition mention may be made of a further intriguing case presented at a clinico-pathological conference (1955) and pertinent to both sections of this discussion. The patient, a girl of 16 years of age, died after an illness lasting eight months and starting with a bloody discharge from the left nostril. The necropsy findings included polyarteritis of the pancreas, healed focal embolic nephritis, and diffuse haemosiderosis of the lungs. Although the details are incomplete, it is interesting to note the comment that the necropsy findings in the lungs are best interpreted as "an incidental early case of haemosiderosis."

Some of the cases in the literature are inconclusive ; for example no glomerulitis was demonstrated in Fienberg's case (1953) or in the first case of Godman and Churg (1954), and the renal lesions described by Klinger (1931) are not characteristic.

Pulmonary Arteritis and Ceelen's Haemosiderosis.-The condition of pulmonary haemo- siderosis has been recognized by Lendrum (1950) as occurring in three forms, one associated with mitral stenosis, one with prolonged left ventricular failure, and the third, the type described by Ceelen (1931), which is a disease mainly of young people and quite unrelated to cardiac disease. This latter type under the title "idiopathic pulmonary haemosiderosis (essential brown induration of the lung)" was reviewed by Wyllie, Sheldon, Bodian, and Barlow (1948), who add seven new cases including a man of 38 years of age. Much of their description of the histopathology of the lungs could be applied exactly to the present case, but they attribute the disease to "an increase of reticulin, collagen and muscle and a decrease of elastic fibres in the pulmonary interstitial tissue, leading to a lack of distensibility of the lungs with consequent peripheral stasis in the capillary bed. This is followed by haemorrhage by diapedesis and deposition of haemosiderin." The histological changes described by Wyllie et al. (1948) are regarded by Lendrum, Scott, and Park (1950) as identical with those they themselves saw not only in one example of Ceelen's disease (since reported by Hutchison, 1954) but also in numerous examples of cardiac haemosiderosis ; they considered that the incrustation and fractures of the elastic tissue were all secondary to the damaging effect of a locally high concentration of iron. These same authors have broadened the concept of Ceelen's disease by the inclusion of the cases described by Kockel (1899), by Sylla (1929), and by Engel and Newns (1939).

The more recent reports on Ceelen's disease include one by Hirrle (1952) with a brief review ; he believes that a congenital hypoplasia of the elastic tissue is the most likely cause of the pulmonary haemorrhages. Defective vasomotor control of the lung capillaries followed by diapedesis

TABLE I

SUMMARY OF FINDINGS IN CASES STARTING WITH RESPIRATORY TRACT GRANULOMA FOLLOWED BY POLYARTERITIS

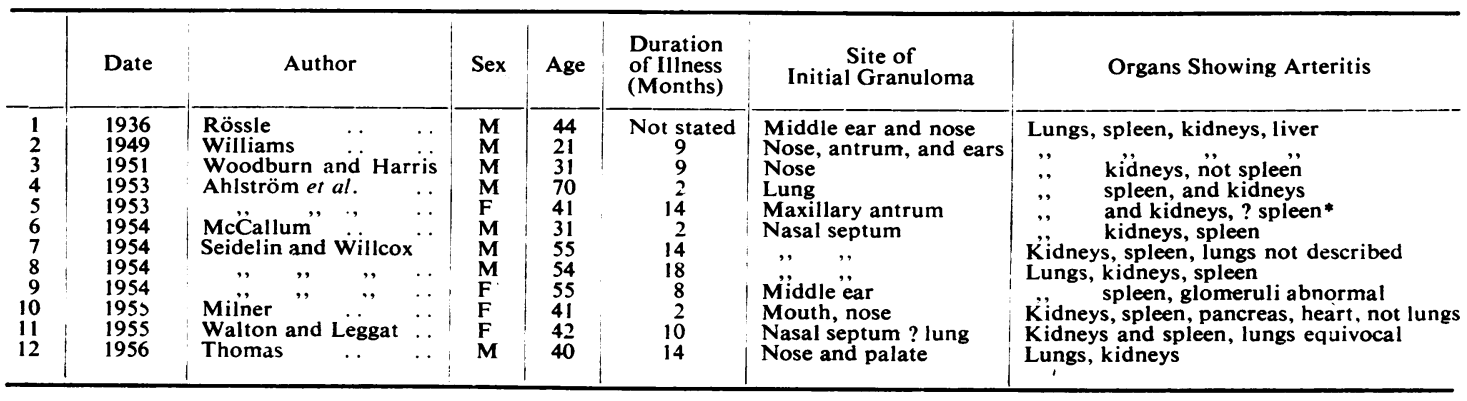

* Yellow areas were noted on the capsule of the spleen, but no histological details of these are given. 
of the erythrocytes is held by McLetchie and Colpitts (1949) to be the primary abnormality, but Hutchison (1954) regards the underlying cause of the haemorrhages as still unknown. Quite a different view is taken by Steiner (1954), who maintains that essential pulmonary haemosiderosis is an allergic disease, in which the pulmonary alveoli represent the shock tissue, and that the lung capillaries react by dilatation and increased permeability in an attack. The fact that the condition was relieved by splenectomy in his case is possibly a confirmation of his view, but the nature of the primary sensitizing agent was not discovered. It may be added here that in the present case the diagnosis of hypersplenism had been suggested and splenectomy was to have been undertaken but for the patient's terminal collapse.

The present case, although obviously not one of Ceelen's haemosiderosis, suggests a possible mechanism for that disease, and one which has apparently not as yet been suggested. On the whole it would seem that the source of the pulmonary haemorrhages in Ceelen's disease has not yet been established, and it is possible that the source tends to be hidden in the mass of blood, fibrin, siderophores, and reactive fibrosis. In the present case the lung in large part presented this same confusing picture, but in it were observed definite examples of arteritis. Indeed, even if these lesions had not been found, their existence could reasonably have been postulated on the basis of the similarity of this case with the reported cases of Wegener's granulomatosis. The hypothesis now offered that hyperergic arteritis may underly the condition of Ceelen's haemosiderosis receives some confirmation from the fact that in one of the reported cases of this diseáse pulmonary arteritis was actually observed; this was in a girl aged 7 (Anspach, 1939) with a three-year history of attacks of cough, haemoptysis, dyspnoea, pallor, and fever up to $100^{\circ} \mathrm{F}$. Radiologically there was diffuse clouding of 'both hilar areas, and at necropsy the lungs showed haemorrhages, haemosiderosis, fibrosis, and necrotizing arteritis. The kidneys were not examined. In two of the cases of Wyllie et al. (1948) the kidneys were found to be normal, as they were also in Hutchison's case (1954). There is thus no real evidence to suggest that Ceelen's haemosiderosis is an incomplete form of Wegener's granulomatosis, but the present study of this latter condition does appear to offer incidentally a clue to the mechanism of Ceelen's haemosiderosis.

\section{Summary}

A case of Wegener's granulomatosis is described with clinical, pathological, and necropsy findings. The discussion is concerned with the recognition of this entity as a distinct variety of polyarteritis nodosa and its relationship to Ceelen's haemosiderosis.

I should like to thank Dr. Joseph Benn for permission to publish this case and Professor A. C. Lendrum for his kind and helpful criticism as well as for the photograph, Fig. 10.

\section{REFERENCES}

Ahlström, C. G., Liedholm, K., and Truedsson, E. (1953). Acta med. scand., 144, 323.

Alexander, F. W. (1954). Ann. Otol. (St. Louis), 63, 171.

Anspach, W. E. (1939). Amer. J. Roentgenol., 41, 592.

Ceelen, W. (1931). In Handbuch der speziellen pathologischen Anatomie und Histologie, vol. 3, pt. 3, p. 20, ed. F. Henke and O. Lubarsch. Springer, Berlin.

Clinico-pathologic Conference (1955). Amer. J. Med., 18, 335.

Engel, S., and Newns, G. H. (1939). J. Path. Bact., 49, 381.

Fahey, J. L., Leonard, E., Churg, J., and Godman, G. (1954). Amer. J. Med., 17, 168.

Fienberg, R.'(1953). Amer. J. clin. Path., 23, 413.

Godman, G. C., and Churg, J. (1954). A.M.A. Arch. Path., 58, 533

Hirrle, W. (1952). Frankfurt Z. Path., 63, 329.

Howells, G. H., and Friedmann, I. (1950). J. clin. Path., 3, 220.

Hutchison, H. E. (1954). Glasg. med. J., n.s. 35, 217.

Klinger, H. (1931). Frankfurt Z. Path., 42, 455.

Kockel, R. (1899). Dtsch. Arch. klin. Med., 64,
Lendrum, A. C. (1950). J. Path. Bact., 62, 555.

Lendrum, A. C. (1950). J. Path. Bact., 62, 555 . Symposium held at Queen's College, Dundee. Livingstone, Edinburgh.

_ Scott, L. D. W., and Park, S. D. S. (1950). Quart. J. Med. n.s. 19, 249.

McBride, P. (1897). J. Laryng., 12, 64.

McBride, P. (1897). J. Laryng., 12, 64.

McLetchie, N. G. B., and Colpitts, G. (1949). Canad. med. Ass. J., 61, 129.

Milner, P. F. (1955). Brit. med. J., 2, 1597.

Rössle, R. (1936). Arch. Ohr.-, Nas.-, u. KehlkHeilk., 142, 193.

Seidelin, R., and Willcox, A. (1954). Arch. Middx Hosp., n.s. 4, 171.

Steiner, B. (1954). Arch. Dis. Childh., 29, 391.

Steiner, B. (1954). Arch. Dis. Childh., 29,
Stewart, J. P. (1933). J. Laryng., 48, 657.

Stratton, H. J. M., Price, T. M. L., and Skelton, M. O. (1953). Brit. med. J., 1, 127.

Sylla, A. (1929). Dtsch. Arch. klin. Med., 163, 309.

Walton, E. W., and Leggat, P. O. (1956). J. clin. Path., 9, 31.

Wegener, F. (1937). Verh. dtsch. path. Ges., 1936, 29, 202.

(1939). Beitr. path. Anat., 102, 36.

Williams, H. L. (1949). Ann. Otol. (St. Louis), 58, 1013.

Woodburn, C. C., and Harris, H. E. (1951). Cleveland Clin. Quart., $18,165$.

Woods, R. (1921). Brit. med. J., 2, 65

Wyllie, W. G., Sheldon, W., Bodian, M., and Barlow, A. (1948). Quart. J. Med., n.s. 17, 25.

Zeek, P. M., Smith, C. C., and Weeter, J. C. (1948). Amer. J. Path., 24,889 . 